\title{
Musculoskeletal Pain in Medical Students Subject to Remote Teaching during the COVID-19 Pandemic
}

\author{
Isabela de Paiva Gomes, Vivian Mitleton, Luiz Gustavo Benedetti Fiorin, \\ Camila dos Santos Leite, Oscar César Pires \\ Medicine Department, Taubaté University, Taubaté, Brazil \\ Email: pgomes.isa@gmail.com, vivian.mitleton@gmail.com, luizgfiorin@gmail.com, camilayantony@gmail.com, \\ oscar.pires@unitau.br
}

How to cite this paper: de Paiva Gomes, I., Mitleton, V., Fiorin, L.G.B., dos Santos Leite, C. and Pires, O.C. (2021) Musculoskeletal Pain in Medical Students Subject to Remote Teaching during the COVID-19 Pandemic. Journal of Biosciences and Medicines, 9, 92-99.

https://doi.org/10.4236/jbm.2021.98008

Received: July 11, 2021

Accepted: August 16, 2021

Published: August 19, 2021

Copyright $\odot 2021$ by author(s) and Scientific Research Publishing Inc. This work is licensed under the Creative Commons Attribution International License (CC BY 4.0).

http://creativecommons.org/licenses/by/4.0/

\begin{abstract}
Musculoskeletal pain is a consequence of repetitive strain, overuse, and work-related musculoskeletal disorders. In 2020, due to the new coronavirus pandemic, social isolation started, and so did online classes in a remote study strategy to replace classroom-based study routines. Thus, students adopted a different physical posture from the usual one for a longer time than usual, representing a possible risk factor for musculoskeletal pain. In this sense, this research aimed to identify the occurrence of musculoskeletal pain in medical students subject to distance learning during the COVID-19 pandemic. A cross-sectional, descriptive and exploratory study was applied through an online questionnaire, using the Google Forms application, to 154 students from the first to the fourth year of the medical course at a university in the countryside of the state of São Paulo. Among the participants, 99 (64.3\%) were female, and 54 (35.7\%) were male individuals with ages ranging from 18 and 34. In regards to the daily study time in sitting position, 83 (55.0\%) reported staying more than 4 hours, 39 (25.8\%) between 2 and 4 hours, and 29 (19.2\%) less than 2 hours still. As for musculoskeletal pain before the pandemic; 98 (63.6\%) reported not feeling it, while 56 (36.4\%) reported being affected by this type of pain. However, after the pandemic, 51 respondents $(33.1 \%)$ continued not to feel anything, whereas 103 (66.9\%) kept on having some type of musculoskeletal pain. The results obtained suggest an increase in musculoskeletal pain during the pandemic however other studies may confirm these findings.
\end{abstract}

\section{Keywords}

Musculoskeletal Pain, Medical Students, Remote Teaching, COVID-19 
Pandemic

\section{Introduction}

Musculoskeletal pain is a consequence of repetitive strain, overuse and workrelated musculoskeletal disorders. These features include a variety of disorders that cause pain in bones, joints, muscles structures or adjacent structures [1].

In a survey conducted by the Brazilian Institute of Geography and Statistics (IBGE), about 27 million Brazilians aged 18 years or over are affected by musculoskeletal pain [2].

However, it is believed that this number does not reflect the reality due to the lack of studies in several population groups. This pain is the main cause of suffering and incapacity for work and causes serious psychosocial and economic consequences [2].

The main causes of pain are posture misalignment, increased body weight, abdominal ptosis, and muscle imbalances. Psychosocial factors such as occupational stress, inadequate social support, monotony of activities, anxiety, depression, among others, will significantly contribute to the occurrence of the problem. As a result, studies indicate increased anxiety, depressive symptoms, high blood pressure, and respiratory problems, in addition to being a cause for temporary or permanent work disability [3] [4].

In 2020, Brazil suffered disruptive social and economic consequences due to the coronavirus pandemic. Among which we highlight the change in the country's educational pattern. Due to the social isolation implemented to prevent the spread of the disease and greater contamination of people, the classroom format classes in all universities in the country were initially interrupted and replaced by online classes in a remote study strategy with their students in their respective homes. That included medical students.

The course study model, which adds up to about 650 semester hours, has been ever since replaced by the remote study strategy, with classes happening on digital platforms, impacting the routine of students from the first up to the fourth year of medical school.

In this way, students were subject to a high number of hours sitting in front of a much larger screen than they were used to. That represents a major risk factor for the causes of musculoskeletal pain. As a side effect, the students began to attend classes for several months sitting in inadequate, vicious, and misaligned postures, most lacking suitable and safe equipment to maintain the proper balance of the body in front of the computer or the phone device.

Additionally, social isolation made it difficult for students to practice physical exercises. It is known that muscle weakness is a rapid phenomenon, occurring in just two days of inactivity [5]. This represents another risk factor for the onset of 
musculoskeletal pain in this population group.

\section{Objective}

The main goal of this paper is to establish the occurrence of musculoskeletal pain and factors related to the time of inadequate posture adopted by medical students subject to remote medical education during the COVID-19 pandemic.

\section{Material and Methods}

This is a cross-sectional study with a descriptive and exploratory approach, carried out with students enrolled from the first to the fourth year of the Medicine course, and remote education during 2020.

Data collection was carried out in December 2020 through an online platform after an access link was sent to the respondents. It is important to mention that all respondents were somewhat related to the researchers.

The choice of the sample for the study was characterized according to the inclusion previously defined criteria. Firstly, an invitation had been sent to 480 students, followed by the submission of the Informed Consent Form (ICF), which was sent along with the invitation for the respondents to access the needed platform. From this selected sample, which had been set by medical students subject only to teaching in the remote format during the period of the pandemic of 2020, an adherence of at least 25\%, which corresponds to about 120 students, was estimated.

The criteria were to students enrolled who were enrolled from the first to the fourth year of the course. Students aged over eighteen, of both sexes, took part in this sample. The main criterion for selection was to approach students who had been taught exclusively online, with daily hours of computer use.

The research was carried out with the approval of the person in charge of the Institution and started only after approval by the Research Ethics Committee (Protocol: 4.463.107/2020) was granted.

The main research tool as questionnaire developed by the researchers using the "Google Forms" online application, which was sent to be accessed through a link that had been previously provided. The questionnaire prompts closed and open questions addressing data such as participant's gender, age, and weight; average daily online study time; the description of musculoskeletal pain before and during the pandemic; most prevalent anatomical pain areas; the used treatment; the practice of physical activity and knowledge regarding the impact of pain on life quality (Appendix). Its validity was based on the Brazilian version of the Standardized Nordic Musculoskeletal Questionnaire [6], and easy-tounderstand questions, regularly used in the course, with clearly defined alternative answers and the reliability tested by the test-retest feature, with the same subjects in different minds producing identical results.

The data that has been obtained were analyzed in percentages and interpreted universally. It was also separated and displayed in the form of absolute numbers 
or percentages and displayed in tables, using the Office Excel computer program.

\section{Results}

The invitation to participate was sent to 8 groups of 60 medical students, adding up to about 480 students, out of which 154 students (32.0\%) responded. The characteristics of the participants are described, as follows in Table 1.

This table describes musculoskeletal pain before and during the pandemic and its characterization in terms of location and frequency.

Before starting the remote teaching model, 98 participants $(63.6 \%)$ did not complain about any type of musculoskeletal pain, but during the pandemic, this percentage changed dramatically, with 51 students $(33.1 \%)$ reporting no pain and 103 (66.9\%) reporting feeling musculoskeletal pain to some extent, with several participants also stating pain in more than one location, as shown in $\mathrm{Ta}$ ble 2 .

The question about the frequency of this pain was developed for the respondents to respond discursively, and probably as a function of the question requiring a discursive answer, many students did not answer completely by explaining both the location and frequency of pain. However, there is a significant increase in this occurrence during remote activities, as described in Table 3.

Table 1. Characteristics of study participants.

\begin{tabular}{ll}
\hline & \multicolumn{1}{c}{ Characteristics of study participants } \\
\hline Medicine course semester & 1 st to 8 th \\
Gender & Female, $99(64.3 \%)$ and male, $55(35.7 \%)$ \\
Age & Between 22 and 34 years old (average of 22 years $)$ \\
Daily study time (online) & $>4$ hours $=86(55.8 \%) ;$ bettween 2 and 4 hours $=39(25.3 \%) ;$ \\
& $<2$ hours $=29(18.9 \%)$ \\
\hline
\end{tabular}

Table 2. Specification of the site of occurrence of musculoskeletal pain before and during the COVID-19 pandemic in 2020.

\begin{tabular}{ccc}
\hline Local & Before the pandemic & During the pandemic \\
\hline Presence of pain & 56 & 103 \\
Lumbar spine & 30 & 68 \\
Shoulders & 13 & 21 \\
Cervical spine & 14 & 33 \\
Others & 12 & 29 \\
\hline
\end{tabular}

Table 3. Specification of the frequency of occurrence of musculoskeletal pain before and during the COVID-19 pandemic in 2020.

\begin{tabular}{ccc}
\hline Frequency & Before the pandemic & During the pandemic \\
\hline Constantly & $\mathbf{0 8}$ & $\mathbf{2 4}$ \\
$\geq 2$ times a week & 17 & 68 \\
Once a week & 10 & 35 \\
Sporadically & 10 & 0 \\
\hline
\end{tabular}


Before the pandemic, musculoskeletal pain complaints were reported in locations such as the lumbar spine, cervical spine, trapezius muscle and shoulders, knees, hips, lower and upper limbs, many of which were associated with the practice of physical exercise.

During the pandemic, the most mentioned pains were in the lumbar and cervical spine and frequently in the shoulders, as one participant explained in his answer: "This heavy shoulder pain increased due to greater anxiety of being alone at home and longer sitting or lying down times, in addition to a reduction in my walking moments in between breaks".

The respondents were also asked about the use of analgesic drugs. Out of the 103 students who answered yes about the occurrence of some type of musculoskeletal pain, the use of pain-relieving drugs was not carried out by 69 of them (66.9\%). An amount of the 34 respondents (33.1\%) reported that they do use some type of drug, with some participants using more than one type of drug, but none of respondents suggested the use of opium derivatives.

As for the evolution of pain, 73 students (70.8\%) believe that pain will cease in the future, reinforcing the association of pain with the period they are going through. It is also important to mention that, despite the difficulties encountered by social isolation during the pandemic, $81.2 \%$ of the students maintained some sports practice. The most commonly reported activities were weight training, functional training, running, walking, pilates and yoga. The remaining amount of students (18.8\%) kept on not practicing any activities.

Regarding the impact of chronic pain on people's life quality, 149 participants responded. Out of this number, 129 (86.6\%) believe in its halt; while 20 (13.4\%) do not think that this condition will be resolved, with a negative impact on life quality standards.

\section{Discussion}

Social distancing, as a consequence of the COVID-19 pandemic that spreads through 2020 and 2021, has forced medical students around the world to adopt information and communication technologies (ICTs) to continue with their study routine. Thus, higher education institutions, in order to make up for this absence of face-to-face lessons in classrooms have increasingly used ICTs and the Internet [7]. The current study also revealed that $55.8 \%$ of students dedicated more than 4 hours per day in front of the screen to study during the pandemic.

Students started to use notebooks and cell phones full time as part of their academic routine, and at these times adopt very unsettling postures, which can cause pain and musculoskeletal changes, especially in the upper limbs and spine [8].

It was show in the results that there was an increase in the number of students with pain complaints related to poor posture. Not only that, but there was also an increase in the frequency of weekly pain in this survey group. Thus, this solution adopted by educational institutions during the pandemic does not come 
without any side effects on students' life quality.

Despite that, the results suggest that musculoskeletal pain caused by remote studies is generally not of great intensity, as $66.9 \%$ did not need to use medication to reduce the reported symptoms. Furthermore, $70.8 \%$ believe that with the end of the remote teaching model, the pain will cease, which reinforces the idea that links pain to this new lifestyle. Therefore, even for a limited period, the distance learning strategy has prompted an increase in the occurrence of musculoskeletal pain in this specific subpopulation.

Not only that, but this current study questioned whether the pandemic has influenced hitherto an increase in the rate of sedentary lifestyle among students. The results showed that $81.2 \%$ of students managed to maintain some practice of physical activity during social isolation. Aerobic strengthening and stretching exercises, even if practiced at home, improve the pain threshold and prevent increased pain in patients diagnosed with chronic pain [9] [10] [11]. Furthermore, it is known to be beneficial for most musculoskeletal pain conditions, including chronic neck problems, osteoarthritis, rheumatoid arthritis, fibromyalgia, myofascial pain, as well as chronic low back pain [12] [13] [14], that being an essential component in combating pain in students.

Thus, it is concluded that there is a link between the occurrence of musculoskeletal pain with longer time in front of the screen in medical students subject to remote education. That happens even to students who don't have sedentary lifestyle, which, on a larger scale, leads to the conclusion that there is a clear impact, for medical students, in the teaching/learning process as well as their life quality.

In the meantime, new discussions can be prompted on the country's universities, so that they can develop ways to better adapt to the current reality that limits the return of in-person classes, and encourage actions to minimize the impact of the new teaching method on the health of students.

Our conclusions are limited by the single-center nature of the study; thus, the results may lack wider applicability due to the small sample size and it can limit the generalizability of the findings. On the other hand, the prospective design of our study minimizes potential sources of bias and incomplete data, which are common problems in retrospective studies.

\section{Conclusion}

The present study found an increase in the occurrence of musculoskeletal pain among undergraduate medical students who spent months adapted to distance learning, as well as to this symptomatology. However, other studies should confirm our results.

\section{Conflicts of Interest}

The authors declare no conflicts of interest regarding the publication of this paper. 


\section{References}

[1] Epstein, S., Sparer, E.H., Tran, B.N., Ruan, Q.Z., Dennerlein, J.T., Singhal, D. and Lee, B.T. (2018) Prevalence of Work-Related Musculoskeletal Disorders among Surgeons and Interventionalists: A Systematic Review and Meta-analysis. JAMA Surgery, 153, e174947. https://doi.org/10.1001/jamasurg.2017.4947

[2] Santos, L.G., Madeira, K. and Longen, W.C. (2017) Prevalence of Self-Reported Spinal Pain in Brazil: Results of the National Health Research. Coluna/Columna, 16, 198-201. https://doi.org/10.1590/s1808-185120171603165890

[3] Paixão, M.D.S., Tassitano, R.M. and Siqueira, G.R. (2013) Prevalence of Musculoskeletal Discomfort and Associated Factors in College Students. Rev Bras Promoc Saúde, 26, 236-244.

[4] Louw, A., Zimney, K., Puentedura, E.J. and Diener, I. (2016) The Efficacy of Pain Neuroscience Education on Musculoskeletal Pain: A Systematic Review of the Literature. Physiotherapy Theory and Practice, 32, 332-355. https://doi.org/10.1080/09593985.2016.1194646

[5] Narici, M., Vito, G., Franchi, M., Paoli, A., Moro, T., Marcolin, G., Grassi, B., Baldassarre, G., Zuccarelli, L., Biolo, G., di Girolamo, F.G., Fiotti, N., Dela, F., Greenhaff, P. and Maganaris, C. (2021) Impact of Sedentarism Due to the COVID-19 Home Confinement on Neuromuscular, Cardiovascular and Metabolic Health : Physiological and Pathophysiological Implications and Recommendations for Physical and Nutritional Countermeasures. European Journal of Sport Science, 21, 614-635. https://doi.org/10.1080/17461391.2020.1761076

[6] Mesquita, C.C., Ribeiro, J.C. and Moreira, P. (2010) Portuguese Version of the Standardized Nordic Musculoskeletal Questionnaire: Cross Cultural and Reliability. Journal of Public Health, 18, 461-466. https://doi.org/10.1007/s10389-010-0331-0

[7] Gomes, V.T.S., Rodrigues, R.O., Gomes, R.N.S., Gomes, M.S., Viana, L.V.M. and Silva, F.S.S. (2020) The Covid-19 Pandemic: Repercussions of Remote Education on Medical Training. Revista Brasileira de Educação Médica, 44, e114.

[8] Morais, B.X., Dalmolin, G.L., Andolhe, R., Dullius, A.I.S. and Rocha, L.P. (2019) Musculoskeletal Pain in Undergraduate Health Students: Prevalence and Associated Factors. Revista da Escola de Enfermagem da USP, 53, e03444. https://doi.org/10.1590/s1980-220x2018014403444

[9] Geneen, L.J., Moore, R.A., Clarke, C., Martin, D., Colvin, L.A. and Smith, B.H. (2017) Physical Activity and Exercise for Chronic Pain in Adults: An Overview of Cochrane Reviews. Cochrane Database of Systematic Reviews, 4, CD011279. https://doi.org/10.1002/14651858.CD011279.pub2

[10] Oliveira, M.A.S., Fernandes, R.S.C. and Daher, S.S. (2014) Impact of Exercise on Chronic Pain. Revista Brasileira de Medicina do Esporte, 20, 200-203. https://doi.org/10.1590/1517-86922014200301415

[11] Bailey, D.L., Holden, M.A., Foster, N.E., Quicke, J.G., Haywood, K.L. and Bishop, A. (2020) Defining Adherence to Therapeutic Exercise for Musculoskeletal Pain: A Systematic Review. British Journal of Sports Medicine, 54, 326-331.

[12] Flynn, D.M. (2020) Chronic Musculoskeletal Pain: Nonpharmacologic, Noninvasive Treatments. Am Fam Physician, 102, 465-477.

[13] Booth, J., Moseley, G.L., Schiltenwolf, M., Cashin, A., Davies, M. and Hübscher, M. (2017) Exercise for Chronic Musculoskeletal Pain: A Biopsychosocial Approach. Musculoskeletal Care, 15, 413-421. https://doi.org/10.1002/msc.1191

[14] Sociedade Brasileira do Estudo da Dor. SBED (2010) Global Year against Musculoskeletal Pain Fact Sheets, Exercise in Management of Musculoskeletal Pain. https://sbed.org.br/wp-content/uploads/2019/02/44.pdf 


\section{Appendix. Questionnaire}

Musculoskeletal pain in medical students subject to remote teaching during the COVID-19 pandemic

Number: Age: Gender: Weight: Height:

1. Do you practice any sporting activities?

( ) Yes ( ) No

If yes, specify the activity and the frequency:

2. How much daily time did you spend studying during the pandemic?
( ) up to 2 hours
( ) between 2 and 4 hours
( ) $>4$ hours.

3. Did you experience any type of musculoskeletal pain before the pandemic?

( ) Yes ( ) No

If yes, specify location and frequency:

Location: ( ) Lumbar spine ( ) Shoulders ( ) Cervical spine ( ) Others

Frequency: ( ) Constantly ( ) $\geq 2$ times a week ( ) Once a week $\quad(\quad)$ Sporadically

\section{Do you feel any type of musculoskeletal pain after the pandemic?}

( ) Yes ( ) No

If yes, specify location and frequency:

Location: $($ ) Lumbar spine ( ) Shoulders ( ) Cervical spine ( ) Others

Frequency: ( ) Constantly $\quad$ ( ) $\geq 2$ times a week $\quad$ ) Once a week $\quad(\quad)$ Sporadically

5. Do you carry out any pain treatment to relieve pain?

( ) Yes ( ) No

If yes, what is the most used therapy? Note: for this question you can check more than one alternative.

( ) Analgesic ( ) Anti-inflammatory ( ) Opioids ( ) Others:

6. Do you believe that pain will cease in the future?

( ) Yes ( ) No

7. Are you aware of the impact of chronic pain on people's life quality?

( ) Yes ( ) No 